\title{
Microstructure Dependent Dislocation Density Evolution in Micro-macro Rolled CNT/Al Composite
}

Behzad Sadeghi

Slovak Academy of Sciences

Pasquale Cavaliere ( $\nabla$ pasquale.cavaliere@unisalento.it)

University of Salento

\section{Research Article}

Keywords: Flake metallurgy, micro/macro rolling, CNTs/Al composite, crystallography texture, CNTs dispersion

Posted Date: October 18th, 2021

DOI: https://doi.org/10.21203/rs.3.rs-982888/v1

License: (c) (1) This work is licensed under a Creative Commons Attribution 4.0 International License. Read Full License 


\title{
Microstructure dependent dislocation density evolution in micro-macro rolled CNT/Al
}

\section{composite}

\author{
Behzad Sadeghi a,b ${ }^{\text {, Pasquale Cavaliere }}{ }^{c, *}$

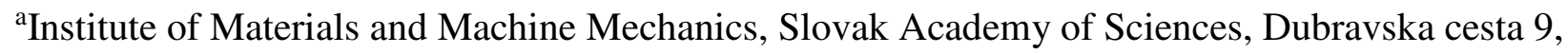 \\ 84513 Bratislava, Slovak Republic \\ ${ }^{\mathrm{b}}$ Centre of Excellence for Advanced Materials Application, Slovak Academy of Sciences, \\ Dubravska cesta 9, 84511 Bratislava, Slovak Republic \\ ${ }^{\mathrm{c}}$ Department of Innovation Engineering, University of Salento, Lecce, Italy
}

*Corresponding author: pasquale.cavaliere@unisalento.it

\begin{abstract}
Flake powder metallurgy combined with micro/macro rolling was employed to produce CNT/Al composites. The effect of deformation mode on the lamellar ultrafine grain structure and on the dislocation density was analyzed. Additionally, a model based on microstructure and processing parameters is proposed to analyze the effect of size, aspect ratio and crystallography texture of the matrix grains on dislocation density. It was shown that the dislocation density depends on CNTs dispersion degree and CNT-aluminum interfacial bonding level as a consequence of micro rolling process, as well as on the grain refinement, crystallography texture, and high aspect ratio resulted from macro-rolling process. It was demonstrated that the micro/macro rolling process provides the lamellar ultrafine grains with higher dislocation storage capability with respect to equiaxed grains. The described process indicated that it could provide good combination between the CNTs dispersion, CNT-aluminum interfacial bonding as well as crystallography texture, size and shape of the matrix grains.
\end{abstract}


Keywords: Flake metallurgy; micro/macro rolling; CNTs/Al composite; crystallography texture; CNTs dispersion.

\section{Introduction:}

Grain refinement has been extensively explored to strengthen metals and metal matrix composites (MMCs). In fact, ultrafine-grained (UFG) and nanostructured metals can be many times stronger than their conventional coarse-grained (CG) counterparts [1], but low ductility is an obstinate roadblock to their practical applications. The low ductility is primarily due to poor dislocation storage and weak strain hardening ability because of suppressing the dislocation activities inside available tiny grains.

Nowadays, there is a focus on UFG aluminum matrix composites in order to obtain more high strength as well as other excellent mechanical properties [2-4]. In this regard, vital prerequisites for making the high strength CNT-Al composites can devote to both relevant parameters to CNTs and microstructure properties of the matrix. Former is composed of dispersion and extent of reaction and the latter regards shape, size, and texture of matrix grain [3-9]. To meet simultaneously all of the parameters, a large number of methods are proposed [4, 10-16] which among all these techniques flake powder metallurgy (flake PM) had been attained much more attention $[3,15,17]$. Jiang et al. [3] showed that flake powder metallurgy is an effective route to achieve a uniform dispersion of CNTs with very little structure damage in the Al matrix. Xu et al. [18]reported a significant level of CNTs dispersion into the Al matrix by employing the combination route of low-speed ball milling (LSBM) and high-speed ball milling (HSBM). As a result, they depicted that flake PM is an efficient route to balance the strength and ductility $[2,19]$.

Many studies have pointed out that the formation of Aluminum carbide $\left(\mathrm{Al}_{4} \mathrm{C}_{3}\right)$ through interfacial reaction is a promising solution to improve load transfer strengthening efficiency [20, 21]. In fact, the existence of the proper surface defects of CNT as a consequence of preparing process is beneficial to improve the comprehensive performance of composite [20,21]. More remarkably, the load transfer 
strengthening mechanism is effectively increased by interfacial bonding between Al-Al grains and CNT-Al [21, 22] due to the anchor effect from the Al matrix [21]. Yu et al. [22] found that in order to improve Young's modulus need to be well controlled both raw CNT quality and CNT/Al interfacial reaction. In a word, by comprising the tensile properties of some CNT/Al by various methods, it could be interpreted that flake PM can provide a better combination of strength and ductility than other CNT/Al composite. It is attributed to good interfacial bonding, structure integrity and uniform dispersion of CNTs [8, 22].

From grain geometry point of view, the size, shape, and crystallography texture are other important microstructure parameters which can also influence the material properties. The grain size of the matrix can be refined as a result of the CNTs dispersion and subsequently leading to increasing the strength. It is now well established that a lamellar grain in aluminum matrix composites (AMCs) could store much more dislocations, resulting in higher strain hardening if compared to a nearequiaxed grain with the same widths [2, 17, 23, 24]. Xu et al. [2] showed that the lamellar grains with higher aspect ratios in CNT/Al composites exhibit more dislocation storage capabilities.

Crystallographic texture can influence the physical/mechanical and chemical behavior of a composite [25]. Obviously, the texture variation as a function of grain size and the extent of plastic strain heterogeneity can be significant in FCC materials especially those have high stacking fault energy like aluminum [26]. Gu et al. [26] showed that major slip mode in the rolled copper depends strongly on the imposed rolling strain which has a large impact on the type of deformation texture. Moreover, the strain incompatibilities in the vicinity of the matrix grains caused by the presence of CNTs have a significant effect on the strengthening of the formed texture. Jazaeri et al. [27, 28] showed that the non-deformable second-phase particles cause the lamellar microstructure break-up and turbulence around a large second-phase particle in the severely rolled aluminum alloy containing particles. They also demonstrated that the texture remote from the reinforcements is a typical rolling texture, whereas in the regions close to the reinforcements, the texture tends to be random. 
Recently, the sintered powder compacts were subjected to post-sintering deformation processes, such as extrusion [8, 29-31], and rolling [32-34], conventional SPD techniques such as ECAP [35], ARB [36], FSP [37], HPT [38, 39], to improve the dispersion and interfacial bonding of CNTs to aluminum matrix. In fact, in the extrusion process as secondary processing due to tri-axial compression stress state the part cross section must be uniform throughout the length of the sample, thereby it leads to generate technical limitations such as sample size, and dimension [40, 41]. It was demonstrated that, in order to obtain high density and reinforcements distribution homogeneity at room temperature, very high strains are required $(>4)[35,42]$. Furthermore, by considering the increasing requirement of the flat products of $\mathrm{Al}$ and $\mathrm{Al}$ based composites instead of the bar products provided by extrusion, ECAP, HPT, it is essential to quest novel SPD techniques.

Compared with extrusion deformation as the most preferred route to fabricate CNT/Al composite, it is expected that conventional rolling process will produce different microstructural evolution due to the multi-steps rolling reduction and only two directions of deformation restriction (bi-axial shearcompression stress state) along the rolling and nominal direction (RD and ND). Such strain condition leads to both the formation of shear texture of $\{001\}<110>$ in the Al flat product [25], and the alignment of the CNTs along the RD in CNT reinforced aluminum composites [33, 43]. Hence, it looks that the level dispersion and extent of reaction of CNTs with aluminum as well as the matrix grain properties after cold rolling of flake PM could differ if compared to those the extruded ones. A few early studied also used the conventional rolling to disperse CNTs [36, 41, 44], however, CNTs were seriously damaged due to the imposed large shear strain. Very recently, Fan et al. [33] used the cold rolling as a secondary deformation process to study the grain refinement of CNT/Al composite fabricated by flake PM. However, their focus mostly was on the superplastic deformation behavior.

Moreover, high angle grain boundary percent (HAGB\%) which in turn depends on the initial grain size, the CNT content and extent of strain, is the most important parameter in collapsing the lamellar architecture corresponding to the severely rolled CNT/Al composite [28]. Actually, by decreasing the 
subgrain size (low angle boundary spacing [27]) with increasing strain, misorientation some of them gradually increase and which may become HAGBs. Additionally, other types of HAGBs such as new HAGBs and pre-existing HAGBs can form. Former is due to different orientation paths during subsequent deformation and latter attributes to increase the grain boundaries with increasing strain. Since elongation of the original grains increase the HAGBs in the microstructure, therefore it is worth emphasizing that the imposed strain during MMR process is effectively affected by grain boundary density which in turn affects the dislocation density. By considering the strain limitations during secondary plastic deformation processes, it is necessary to understand how way and how much can be applied a huge plastic strain ( $>4$ ) to a material (herein CNT/Al composite) to obtain a good coordination of CNT dispersion, reaction CNT-Al, and microstructure properties of the matrix grains such as size, geometry and crystallography texture.

Here, it will be proposed a microstructural property-based model which is containing the lamellar ultrafine-grains to calculate the dislocation density with relation to grain size, shape and crystallography texture. To this end, the required strain for achieving to a lamellar UFG architecture during preparing process is calculated. The nanoscale architecture is produced by means of a novel and smart SPD technique derived from flake PM technique that so-called micro-macro rolling (MMR) process. Actually, a strategy of task allocation two-stage rolling, one in micro-scale and the other in macro-scale is used to tailor lamellar UFGed architecture of CNT/Al composite. The effect of different reductions of macro-rolling process on the CNT dispersion, the reaction extent of CNT with aluminum as well as the size, shape, and crystallography of the matrix grains are studied.

\section{Experimental procedure}

Spherical aluminium powders with mead diameter of $40 \mu \mathrm{m}$ and CNTs were selected as the raw materials. 1.0 and $1.5 \mathrm{wt} \%$ of CNTs is chosen as appropriate content for reinforcing. Flake PM technique via solution approach and following conventional rolling process was employed to 
fabricate UFGed CNTs/Al composite. Firstly, to ensure the breaking of CNTs clusters, they were dispersed in ethanol, assisted by an ultrasonic shaker for $1 \mathrm{~h}$ to get a gel-like dispersion. After that, the raw Al powders are added in the gel-like CNTs-ethanol solution, stirred and then dried in vacuum at $70^{\circ} \mathrm{C}$ for $2 \mathrm{~h}$ to obtain $\mathrm{CNTs} / \mathrm{Al}$ spherical powders. To make the composite, flake PM via a dualspeed BM route $[18,45]$ conducted using a planetary ball mill at low-speed BM(LSBM) at 160rpm for $8 \mathrm{~h}$, hereafter denoted as 160/8, followed by high-speed BM (HSBM) at 270rpm for 1h, hereafter denoted as 270/1, in an argon atmosphere at $1 \mathrm{~atm}$. Preliminary experiences demonstrated that the combination of LSBM and HSBM lads to uniform CNT dispersion in Al flakes thanks to LSBM, and good bonding of CNT/Al flakes thanks to HSBM. Vacuum hot pressing (VHP) was employed for the consolidation of the composite powders. Powders were firstly cold pressed before sintering at $550^{\circ} \mathrm{C}$ for 2 hours in a graphite die. The processing of the studied composites is shown in Figure 1.

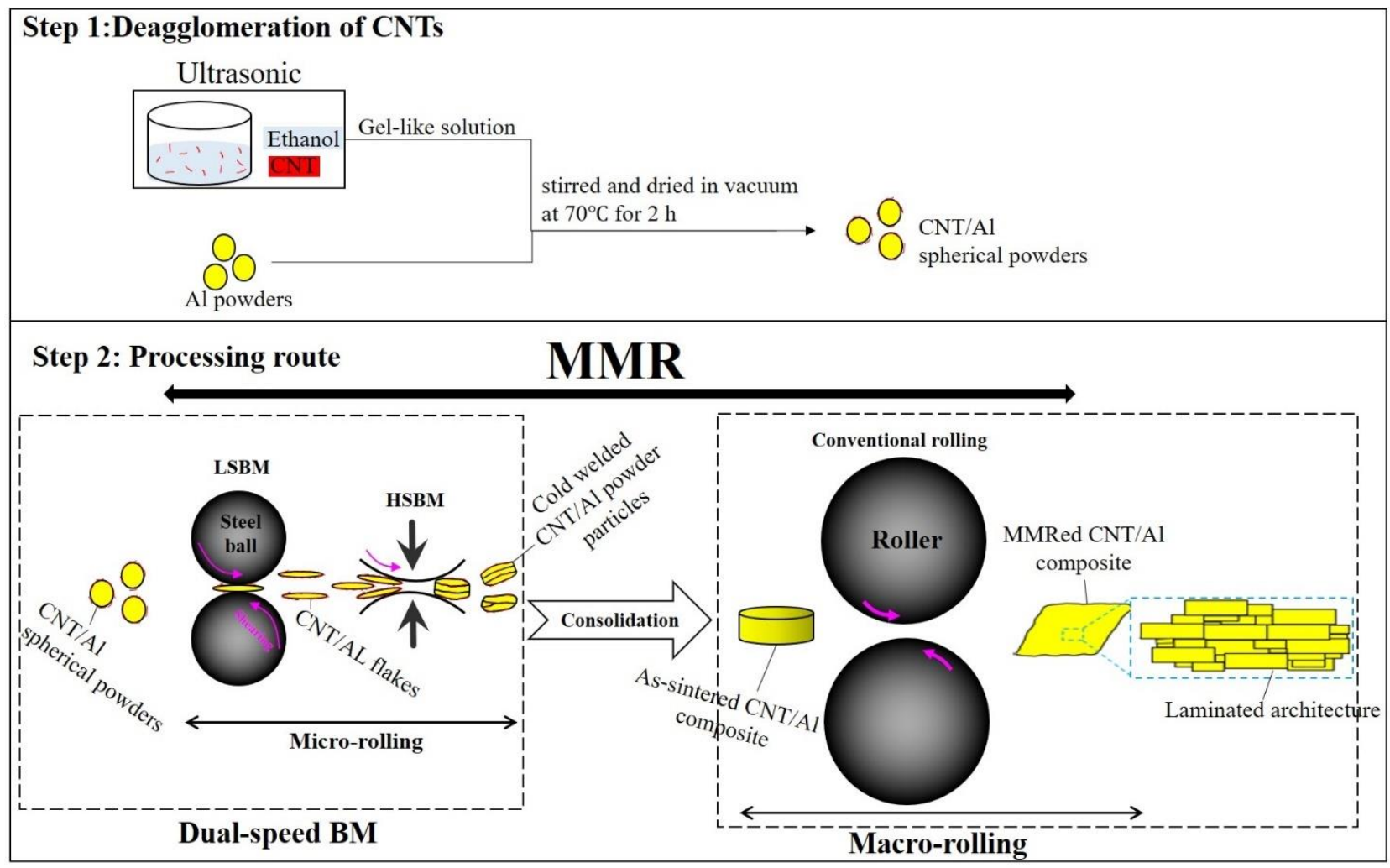

Figure 1: processing schematic of dual speed flake PM of CNT/Al composite during MMR. 
The rolling processing conditions sequence is shown in table 1.

Table 1. Processing conditions employed to produce the CNTs/Al composites.

\begin{tabular}{|c|c|c|c|c|c|}
\hline \multirow{2}{*}{ Material } & \multirow{2}{*}{ CNT, } & \multicolumn{2}{|c|}{ Micro-rolling } & \multicolumn{2}{c|}{ Macro-rolling } \\
\cline { 3 - 6 } & \multirow{2}{*}{ wt.\% } & LSBM & HSBM & Thickness & Temperature \\
& & & & Reduction $(\%)$ & $\left({ }^{\circ} \mathrm{C}\right)$ \\
\hline Al & $1.0,1.5$ & selective & $270 \mathrm{rpm}, 1 \mathrm{~h}$ & $10,20,30,40,50$ & 150 \\
\hline
\end{tabular}

Macro-rolling was performed to different reductions in thickness $(10,20,30,40$ and $50 \%)$ at $150{ }^{\circ} \mathrm{C}$ which was below recrystallization temperature for pure $\mathrm{Al}[46,47]$. For comparison, CNTs/Al spherical powders are milled at $270 \mathrm{rpm}$ for $9 \mathrm{~h}$ and then sintered following the same macro rolling condition to evaluate the effect of micro-rolling process on the size, shape and crystallography texture of the matrix grains as well as the CNTs dispersion level and interfacial bonding degree. Such a combined process regime of MMR makes flake PM applicable to fabricate special UFG architectures otherwise cannot be achieved by present methods.

To characterize the microstructure of CNT/Al powders and composites, FESEM and HRTEM images are used. Since, EBSD can examine bigger areas compared to TEM images, thus it can be used to investigate the grain boundaries evolution during MMR process. The mean grain size, the fraction of low angle grain boundaries (LAGBs), and high angle grain boundaries (HAGBs) are obtained using EBSD data and discuss in details. Boundaries with misorientation between $2^{\circ}$ and $15^{\circ}$ were defined as LAGBs and those of misorientation $>15^{\circ}$ as HAGBs. To investigate the impacts of the microstructure and crystallography orientations relevant to the architecture of the MMRed composites, XRD (Empyrean, Palmernaco) patterns and SEM images (Mira 3, Tescan) equipped by EBSD instrument (Nordlys Max3, Oxford Instruments) were employed for the microstructural characterization of the samples. The mean grain size, the fraction of low angle grain boundaries (LAGBs), and high angle grain boundaries (HAGBs) are obtained using EBSD data and discuss in 
details. Boundaries with misorientation between $2^{\circ}$ and $15^{\circ}$ were defined as LAGBs and those of misorientation $>15^{\circ}$ as HAGBs. To investigate the impacts of the microstructure and crystallography orientations relevant to the architecture of the micro-macro rolled composites, EBSD images is taken. The dislocation structures were examined by transmission electron microscopy (TEM, JEOL 2100F), where the TKD and TEM specimens were prepared by the lift-out method using focused ion beam system (FIB, FEI Scios).

Tensile and hardness tests were performed to measure the materials mechanical properties. Tensile samples were cut from the rolled composite foils with $50 \mathrm{~mm}$ length, $4 \mathrm{~mm}$ width and $15 \mathrm{~mm}$ gauge length at a constant strain rate $0.5 \mathrm{~mm} / \mathrm{min}$ in a direction parallel to the rolling one (RD). Vickers hardness (HV) tests were conducted on polished cross section parallel to the rolling surface, under an applied load of $50 \mathrm{~g}$ for $10 \mathrm{~s}$. The hardness measurements were done on seven different random points of the rolled surface.

\section{Results and discussion}

\section{Deformation model}

Concerning the overall strain of MMR process, it is approximately consistent with the sum of the overall reduction of bulk materials during both micro-rolling $\left(\varepsilon_{\text {micro }}\right)$ and macro-rolling process ( $\left.\varepsilon_{\text {macro }}\right)$. Therefore, the total strain imposed can be decomposed into its micro rolling induced strain and macro rolling induced strain parts as given in Eq.1.

$\varepsilon_{t}=\varepsilon_{\text {micro }}+\varepsilon_{\text {macro }}$ 
During milling the powder evolution follows five different stages [1]. Among all stages, the particle flattening (the first stage) results from plastic deformation, leading to change the spherical aspect to plate (flake)-shape appearance. The typical HSBM method caused severe damage and excessive interfacial reaction of CNTs, while LSBM enhances the dispersion of CNTs and minimizes the damage. The amount of strain that a metallic particle experienced by one collision can be expressed as in Eq. $2[2,3]$ :

$\varepsilon=-\ln \left\{1-\frac{\vartheta_{B} R_{B}}{h}\left(\frac{\rho_{B}}{H_{v}^{V}}\right)^{1 / 2}\right\}$

Where $\mathrm{h}=2 d_{p}$ [48] where $d_{p}$ is the mean diameter of the as-received powder, $\vartheta_{B}$ is the balls speed $(\mathrm{m} / \mathrm{s}), R_{B}$ is the ball radius, $\rho_{B}$ is the balls density, and $H_{v}^{V}$ is the vital Vickers hardness.

The number of collisions experienced by each particle during ball milling process can be calculated through Eq. 3.

$\mathrm{N}=\frac{3}{4 \pi} \frac{A f_{b m} \rho_{p}(C R) t}{\rho_{B} R_{B}}$

Where $A$ is a constant related to the milling instrument, $C R$ is defined as the charge ratio (mass of balls/mass of powder), $f_{b m}$ is the frequency of milling, $\rho_{p}$ is the powder density and $t$ is the time of the milling.

The frequency of collisions in a planetary ball milling can be expressed as in Eq. 4:

$f_{b m}=K N_{B}\left(S_{d^{-}} S_{V}\right)$ 
Where $N_{B}$ si the number of balls and $\mathrm{K}$ is a constant and was evaluated to be approximately 1.5 [49]. $S_{d}$ and $S_{V}$ are the rotational speed of disk of the mill and of the vial, respectively. And $S_{V} \sim-2 S_{d}$ for $500 \mathrm{ml}$ planetary ball milling system in our lab.

The time required to flatten the spherical aluminium powder particles is proportional to the time interval between different ball collisions, $\tau$ (in minutes), that can be expressed by Eq. 5 [50]:

$t_{\text {flatten }} \propto \tau=\frac{1}{60 f_{b m}} \frac{V_{P}}{V_{c}}$

Where $V_{P}$ and $V_{C}$ are the volume of powder associated with each ball and the powder volume affected by a collision, respectively. $\frac{V_{P}}{V_{c}}$ can be calculated by Eq. 6 :

$\frac{V_{P}}{V_{c}}=\frac{4}{\sqrt{3}}\left(\frac{R_{B} \rho_{B}^{1 / 2}\left(H_{p}^{V}\right)^{1 / 2}}{\rho_{p}(C R) h \vartheta_{B}}\right)$

Where $h=2 d_{p}$.

The volume fraction of aluminium particles can be defined by Eq. 7 [51] :

$f_{A l}=\frac{\operatorname{vol}_{A l}}{\operatorname{vol}_{A l}+\operatorname{vol}_{C N T}+\operatorname{vol}_{B a l l}+\operatorname{vol}_{P C A}}$

Where $v o l_{A l}, v o l_{C N T}, v o l_{P C A}$ and $v o l_{B a l l}$ is the volume fraction of aluminium powders, CNTs, PCA and balls in LSBM process.

The variation of the powder hardness during milling is a fundamental parameter affecting the imposed strain to powder. Maurice et al. [52] showed that the variation of hardness of milled powder by increasing imposed strain during milling can be calculated by eq. 8 . 
$H_{p}^{V}=H_{0}^{V}+3 K \varepsilon^{n}$

The strain is determined from Eq. 9.

$\varepsilon=-\ln \left\{\frac{h-\alpha_{r}}{h}\right\}$

And $\alpha_{r}$ is the deformation of the powder trapped between two balls and is calculated by Eq. 10 .

$\alpha_{r}=\vartheta_{B} R_{B}\left(\frac{\rho_{B}}{H_{0}^{V}}\right)^{1 / 2}-\frac{r^{2}}{R_{B}}$

Where $H_{0}^{V}$ is the initial powder hardness, $K$ is the strength coefficient, $n$ is the work-hardening exponent of powder and $r$ is the distance from the center of two powders in contact.

As a first assumption, the variation of the hardness onto the powder surface will be only considered. In such condition, $r=R_{p}$.

Therefore, the strain imposed to the overall aluminium powder particles during LSBM as a microrolling model can be expressed as Eq. 11:

$\varepsilon_{\text {micro }}=\varepsilon \times \mathrm{N} \times \tau \times f_{A l}$

Therefore, by using Eq. 1-5, $\varepsilon_{\text {micro }}$ can be re-written as in Eq. 12:

$\varepsilon_{\text {micro }}=-\ln \left\{1-\frac{\vartheta_{B} R_{B}}{h}\left(\frac{\rho_{B}}{H_{v}^{V}}\right)^{1 / 2}\right\} \times \frac{1}{45 \pi}\left(\frac{t\left(H_{p}^{V}\right)^{1 / 2}}{\rho_{B}^{1 / 2} h \vartheta_{B}}\right) \times f_{A l}$ 
Where $\mathrm{A}$ is a constant related to the milling instrument.

The reduction ratio for normal rolling can be obtained as described in Eq. 13:

$R=\frac{h_{0}-h_{f}}{h_{0}}$

Where $h_{0}$ and $h_{f}$ are the original thickness and final thickness of the specimens, respectively.

By considering each of the matrix powders experiences the same deformation, Tan et al. [53] showed that ratio of the original transverse length, $d_{0}$, and the final short transverse length, $d_{F}^{S}$, should be given by Eq. 14 .

$\frac{d_{0}}{d_{F}^{S}}=\sqrt{R}$

After applying the macro-rolling, short-transverse length of matrix powder, $d_{F}^{S}$, and the original matrix powder size, $d_{O}$ should have an approximately same ratio with that of the change in thickness (Eq. 15),

$\frac{d_{0}}{d_{F}^{s}}=\frac{h_{0}}{h_{f}}$

Therefore, it can be expected that the imposed strain during macro-rolling process to the materials can be expressed as Eq. 16.

$\varepsilon_{\text {macro }}=\frac{h_{0}-h_{f}}{h_{0}}=\left\{1-(\sqrt{R})^{-1}\right\}$ 
Therefore, it can be concluded that overall strain imposed after MMR process is given by Eq. 17 .

$\varepsilon_{t}=-\ln \left\{1-\frac{\vartheta_{B} R_{B}}{h}\left(\frac{\rho_{B}}{H_{v}^{V}}\right)^{1 / 2}\right\} \times \frac{1}{45 \pi}\left(\frac{t\left(H_{p}^{V}\right)^{1 / 2}}{\rho_{B}^{1 / 2} h \vartheta_{B}}\right) \times f_{A l}+1-(\sqrt{R})^{-1}$

In the proposed model, the focus will be on the strengthening resulted from the evolution of dislocation during plastic deformation strain $\left(\varepsilon_{t}\right)$. Therefore, since then, it will be paid to the impacts of the plastic strain imposed during MMR process on the shape, size and crystallography texture parameters of the matrix. Therefore, the contribution of MMR process on the generation of dislocations should be considered separately, namely as in Eq. 18.

$\rho_{M M R}=\rho_{\text {micro-rolling }}+\rho_{\text {macro-rolling }}$

The formation of several domains which in turn reflects the different orientations inside grains, are directly affected by the micro-strain imposed during micro-rolling process. Actually, the misorientation between the domains inside the CNTs/Al composite particle ranges between that of low angle grain boundaries (LAGBs) to high angle grain boundaries (HAGBs). In early stages of milling, the LAGBs first increases due to the produced dislocation walls and subgrains, and then decreases due to the rearrangement of LAGBs through dynamic recovery.

However, it is found that the LAGB extent in aluminium alloys remains approximately constant at strains larger than 1-2 [27]. Many HAGBs formed, but they did not evolve into new grains banding the grain interiors in order to create just regions of different orientation. Hence, by progressing the milling, the increase not only in the density of LAGBs but also in the density of HAGBs occurred. The former is arisen from the large changes in orientation inside the lamellar grains and latter is 
originated from the gradual increasing of the misorientation in subgrain boundaries as a consequence of the increased dislocations density.

To calculate the dislocation density caused by $\rho_{\text {micro-rolling }}$, the dislocation density evolution in grain boundaries and grain interior should be considered. Hence, it should be first calculated the number of dislocations arriving at grain boundaries $\left(n_{0}\right)$ during imposed plastic strain $\left(\rho_{\text {micro-rolling }}\right)$. Besides, the effect of deformation geometry on the density of HAGBs should also be considered in the micro-rolling process. To this end, the situation is summarized in Eq. 19 [54$56]$.

$\frac{d n_{0}}{d \varepsilon_{\text {micro-rolling }}}=\frac{M \lambda}{b}\left[1-\frac{n_{0}}{n_{0}^{*}}\right]$

Where $\lambda$ is the average distance between slip bands which is equal to the width of lamellar grain. $n_{0}^{*}$ is the maximum number of dislocations or screening at a GB and $\lambda$ is the average length of dislocation loops. $M$ and $b$ are Taylor factor and Bergers' vector for aluminum.

Recently, Razavi-Tousi et al. [57] proposed an interesting technique to calculate the grain boundary density according to processing the misorientation data for EBSD patterns. The method is summarized in Eq. (20).

$$
\rho_{G B i}=\frac{N_{i}}{N_{T} \times d_{S} \times R_{S}}
$$

Where $\rho_{G B i}$ is the boundaries density with misorientation $i$ per area, $N_{i}$ the frequency of counted pixels with misorientation $i, d_{s}$ the step size of EBSD image, $N_{T}$ the total pattern pixels number and 
$R_{S}$ is the indexed pixels to the total number of pixels ratio. To calculate the dislocation density of involved in grain boundaries per area , $\rho_{\text {GBi dislocation }}$, can be expressed by Eq. 21 .

$\rho_{G B i-\text { dislocation }}=\frac{\rho_{G B i}}{n_{0}}$

Razavi et al. [57] proposed a technique to calculate the geometry effect of deformation on the increase in the HAGBs density. Similarly, it can be used in our case concerning the dependency of the geometry effect on LAGBs density. To this end, HKL software is used to measure the average aspect ratio of the grains both with LAGBs (Eq. 22) and HAGBs (Eq. 23).

$G_{H A G B}=\frac{1+S_{H A G B}}{2 \sqrt{S_{H A G B}}}$

$G_{L A G B}=\frac{1+S_{L A G B}}{2 \sqrt{S_{L A G B}}}$

Where $S_{L A G B}$ and $S_{H A G B}$ are the average aspect ratio of the subgrains and grains with LAGBs and HAGBs, respectively. Therefore, the contribution of grain boundaries in increasing the dislocation density during MMR process, can be expressed from Eq. 24:

$\rho_{\text {GBi dislocation }}=\left\{\rho_{\text {GBi dislocation }}{ }^{L A G B} \times G_{L A G B}\right\}+\left\{\rho_{\text {GBi dislocation }}{ }^{H A G B} \times G_{H A G B}\right\}$

In ultrafine-grain CNTs/Al composites, the evolution of dislocation inside grain interior $\left(\rho_{G I}\right)$ during the deformation process is governed by the following dynamic process, due to dislocation-dislocation pinning, annihilation of dislocations as a consequence of dynamic recovery and an additional term (- 
$\left.k_{e} \rho_{S S D}\right)$ which reflect dynamic recovery of additional dislocation at GBs due to decrease grain size $[5,58]$. During the process of deformation, the evolution of dislocations density for a given strain $\left(\varepsilon_{\text {micro-rolling }}\right)$ can be given from Eqs. 25 and 26.

$\frac{d \rho_{G I}}{d \varepsilon_{\text {micro-rolling }}}=\frac{d \rho^{+}{ }_{G I}}{d \varepsilon_{\text {micro-rolling }}}+\frac{d \rho^{-}{ }_{G I}}{d \varepsilon_{\text {micro-rolling }}}$

$\frac{d \rho_{G I}^{+}}{d \varepsilon_{\text {micro-rolling }}}=\frac{M k_{G B}}{b w_{A l} / \cos \theta}$

Where $w_{A l}$ is the lamellar UFG width of aluminium. $\theta$ is the average angle between the slip direction and the tensile direction, which is assumed to be $45^{\circ}$ as shown in figure 2 .

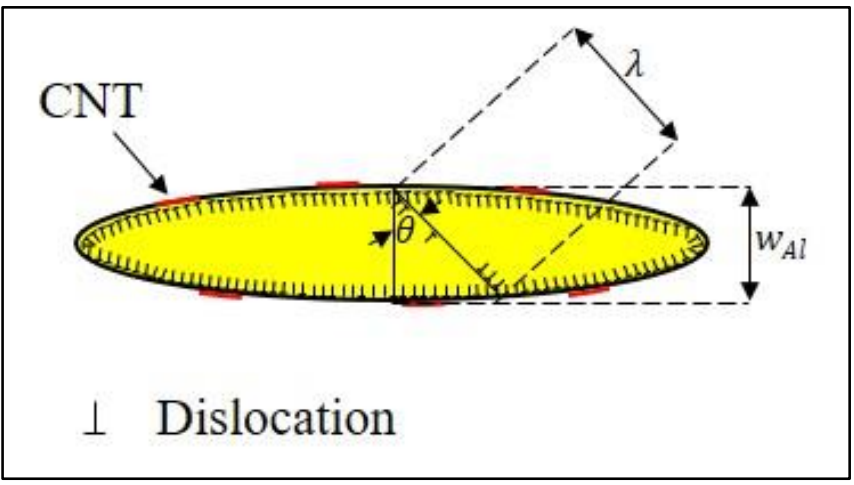

Figure 2: Illustration of the dislocations behaviour.

Owing to the presence of CNTs, the strain incompatibility between different grains should be considered, therefore $k_{G B}=1.25$, otherwise $k_{G B}=1$ if only the grain boundaries dislocations are considered [59].

The dislocation annihilation in FCC metals can be described by Eq. 27. 
$\frac{d \rho_{G I}^{-}}{d \varepsilon_{\text {micro-rolling }}}=\mathrm{M} \rho_{G I}\left\{\frac{k_{2}}{b}+\frac{k_{3}}{b w_{A l}^{2}}\right\}$

Where $\rho_{G I}$ is the dislocation density of the grain interior which can express as in Eq. 28.

$$
\rho_{G I}=\frac{M \varepsilon_{\text {micro }}}{b w_{A l} / \cos \theta}
$$

$k_{1}$ defined as the dislocation storage factor and is in the range of $1 \times 10^{13}-1 \times 10^{14} m^{-2}[60]$.

The terms $k_{2}$ and $k_{3}$ are parameters directly linked to cross slip of screw dislocation and annihilation coefficient of edge dislocation accumulated. $k_{2}$ can be calculated by $\frac{\psi}{b}$, where $\psi$ is the proportionality factor. The term $k_{3}$ corresponds to the grain boundary diffusion coefficient and the effective forest hardening effects of grain boundary dislocations. The terms $k_{2}$ and $k_{3}$ are considered by 0.025 [61] and $0.00423 \mathrm{~m}$ for CNTs/metal composites.

The decrease of grain size and the change of the aspect ratio could effectively affect the dislocation density. Thereby, in the case under study where the grains are UFGed having a non-isotropic grain shape, the effective grain size should be defined. Hence, $d_{e f f}$ is the effective grain size of the matrix by taking into account both the average dislocation loop length, $g$, and the average area sweap by dislocation, $S_{\text {dis }}$. Therefore, it can be defined by Eq. 29 .

$d_{e f f}=\left(\frac{4 S_{d i s}}{g}\right)^{2} \times \frac{1}{\sqrt[3]{V}}$

Where $\mathrm{g}=\pi\left(d_{C N T}\right)$ and $V$ is the volume of the oblate sphere that is calculated by Eq. 30 .

$V=\frac{4 \pi}{3}\left(e c^{2}\right)$ 
Where $c$ and $e$ are half of the length and width of the micro-rolled grain.

Since the majority of the lamellar grains sectioned by transverse LAGBs as well as HAGBs throughout the grains during ball milling process, thus the average area sweap by dislocation, $S_{d i s}$, can be expressed by Eq. 31 .

$S_{\text {dis }}=\pi(c)^{2}$

Therefore, basing on these considerations, Eq. (28) can be re-written through Eq. 32

$\rho_{G I}=\frac{M \times \varepsilon_{\text {micro }} \times \cos \theta \times S_{\text {micro }} \text {-rolling }}{b d_{\text {eff }}}$

Where $S_{\text {micro-rolling }}$ is aspect ratio for the lamellar aluminium grain after micro-rolling process.

Micro-rolling process originally resulted in the flattening of powder particles as a consequence of plastic deformation imposed during transferring the kinetic energy of balls to powder particles; no overall texture is developed by imposing deformation due to continuously change of stress direction and deformation mode for each particle. However, secondary plastic deformation process, as is here macro-rolling process, is responsible to form the crystallography texture. Furthermore, in many FCC materials, dislocation density and distribution depend on crystallography texture of the grains with respect to the stress axis [62].

Therefore, it should be also considered the contribution of crystallography texture parameter on the dislocation density related to the macro-rolling process. To this end, the percentage of $(h k l)_{R D}$ oriented grains along rolling direction, $P O_{h k l}$, can be calculated by Eq. 33 . 
$P O_{h k l}=\frac{I_{h k l}}{\sum I_{h k l}} \times 100$

Where $\sum I_{h k l}$ is the sum of the Bragg reflections intensity of each (hkl). Usually, $\{001\}<110>$ texture forms as the rolling shear texture in the $\mathrm{Al}$ flat are produced. Hence, it seems that the rolling direction is consistent with the direction of $\langle 110\rangle$ which is the major direction of shear texture in FCC materials. Additionally, for our work, (hkl) represents three most intensive Brag reflection crystal faces (111), (200) and (220).

During plastic deformation strain, $\varepsilon_{\text {macro-rolling }}$, the density of the dislocations can be expressed by Eq. 34.

$\rho_{\text {macro-rolling }}=\frac{M \varepsilon_{\text {macro }- \text { rolling }}}{b \lambda}$

Where $\mathrm{M}$ is the Taylor factor and $\lambda$ is the average glide distance of the dislocations. Since, the distance between the center and edge of the lamellar UFGs is the minimum distance for gliding the dislocations, it is hence logical to assume that the short transverse length of matrix grain is equal to the average glide distance of the dislocations. Hence, it can be expressed by Eq. 35 .

$\lambda=\frac{w_{A l}}{\cos \theta}$

Therefore, the density of the dislocations is given by Eq. 36 .

$\rho_{\text {macro-rolling }}=\frac{\left\{1-(\sqrt{R})^{-1}\right\} \times M \times \cos \theta}{b \times w_{A l}} \times P O_{h k l}$

By and large, the overall density of dislocation resulted from plastic deformation imposed during MMR process can be calculated through Eq. 37. 


$$
\begin{aligned}
& \rho_{M M R}=\left\{\rho_{\text {GBi dislocation }}{ }^{L A G B} \times G_{L A G B}\right\}+\left\{\rho_{\text {GBi dislocation }}{ }^{H A G B} \times G_{H A G B}\right\}+\frac{M k_{G B}}{b w_{A l} / \cos \theta}+\mathrm{M} \\
& \left(\frac{M \times \varepsilon_{\text {micro }} \times \cos \theta \times S}{b d_{\text {eff }}}\right)\left\{\frac{k_{2}}{b}+\frac{k_{3}}{b w_{A l}^{2}}\right\}+\left\{\frac{\left\{1-(\sqrt{R})^{-1}\right\} \times M \times \cos \theta}{b \times w_{A l}} \times P O_{h k l}\right\}
\end{aligned}
$$

\section{Results and discussion}

\section{Microstructural evolution}

The microstructure of the CNTs/Al composite with $1.0 \%$ of carbon nanotubes as a function of the thickness reduction during hot rolling is shown in Figure 3. From the first glance, it can be found that the grains are mostly consisted of UFG grains $(>100 \mathrm{~nm})$ while some rod-like $\mathrm{Al}_{4} \mathrm{C}_{3}(<10 \mathrm{~nm}$ in diameter) are also visible. Plus, the average of grain size of $\mathrm{Al}$ is decreased as the thickness reduction increases. However, formation of rod-like $\mathrm{Al}_{4} \mathrm{C}_{3}$ is inevitable as a consequence of compressing force and collision frequency which were directly proportional to the milling speed $[18,63]$ as well as pressure caused by conventional rolling process [33].
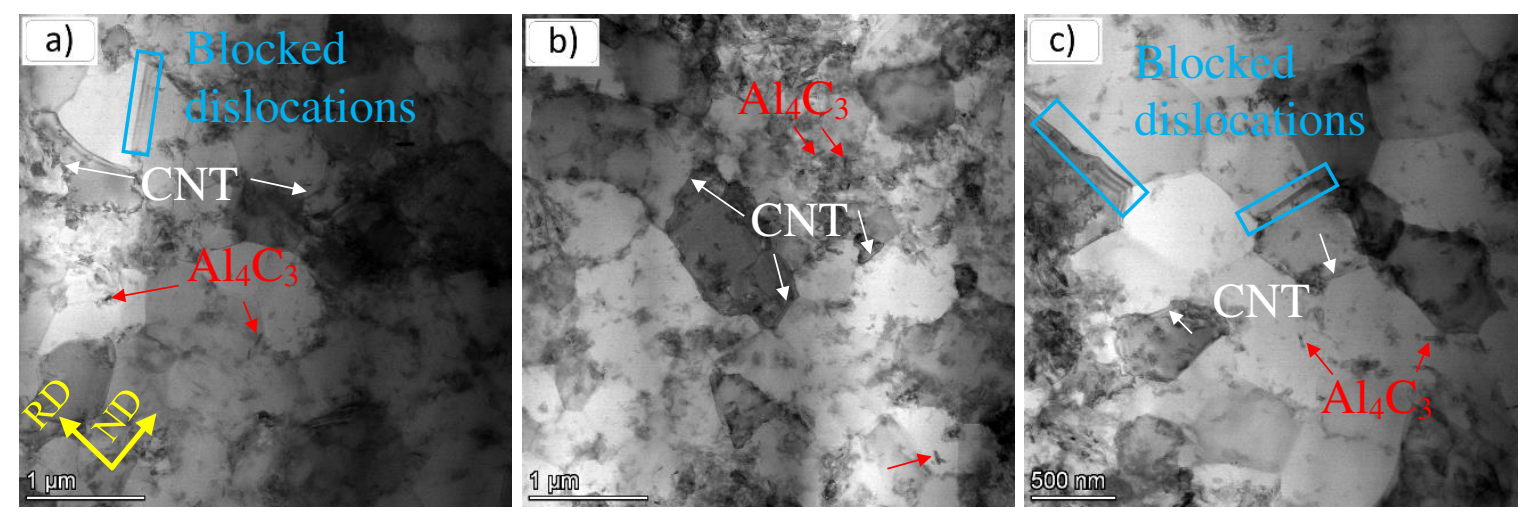

Figure 3: CNTs/Al composite after $10 \%$ (a), $30 \%$ (b) and $50 \%$ of thickness reduction (c); the microstructure belongs to a percentage of CNTs of 1.0 .

The microstructure of the CNTs/Al composite with $1.5 \%$ of carbon nanotubes as a function of the thickness reduction during hot rolling is shown in Figure 4. There is no agglomeration of CNTs in content of CNTs and they are mainly distributed along the grain boundaries in the CNT/Al composites 
that was consistent with previous studies $[63,64]$. The addition of CNTs leads to the significant increase of UFG grains, and with the CNT content increasing, the proportion of UFG grains increases in $\mathrm{CNT} / \mathrm{Al}$ composites as the thickness reduction increases. From the perspective of the overall grain size distribution, as the CNT content increases, the grain size becomes smaller which attributed to the strong pinning effect of CNTs. Especially when the CNT content is $1.5 \mathrm{wt} . \%$, all the grain sizes are smaller than 300nm and showed an acceptable homogeneity in the UFG range.

Developing the thickness reduction from 10\%, 30\%, and 50\% causing a large number of CNTs are singly dispersed on the grain boundaries, as shown by the white arrow, while a small amount of $\mathrm{Al}_{4} \mathrm{C}_{3}$ nanorods, as shown by the red arrow, are distributed in the grain interiors at all thickness reductions. A close inspection of the figures 3 and 4, can be depicted that the CNT-enriched zones are formed near the grain boundaries due to thermodynamically equilibrium.
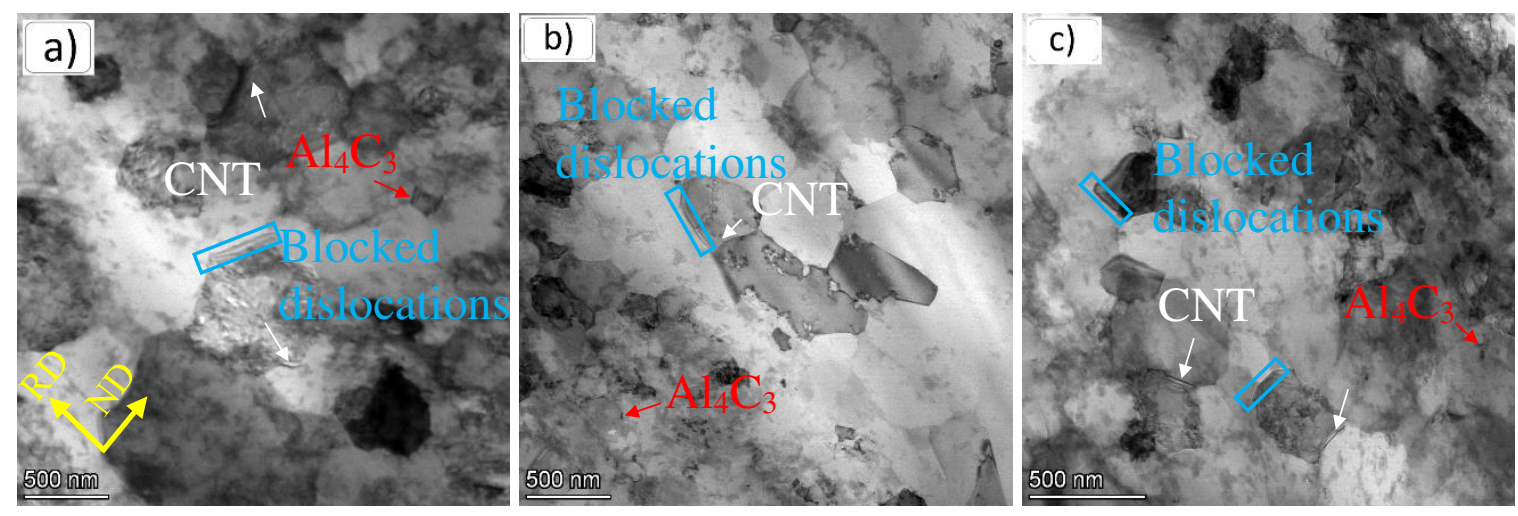

Figure 4: CNTs/Al composite after $10 \%$ (a), $30 \%$ (b) and $50 \%$ of thickness reduction (c); the microstructure belongs to a percentage of CNTs of 1.5 .

Under flake BM condition and subsequent conventional rolling process as a high strain rate regime, dislocations are generated as a consequence of intrinsic and non-intrinsic incompatibilities such as different crystallographic orientation in grain boundaries, domains as well as the presence of CNTs at grain boundaries, giving rise the driving stress for increasing the internal stresses of the UFG grains. 
Grain boundaries and CNT-Al interfaces are the main long-range barriers to dislocation motion that cannot be overcome by thermal activation especially [18]. Hence, impeding and piling up the dislocation in such border regions result in a much higher dislocation density in the CNT-enriched regions. Moreover, short-range barriers such as impurity atoms, forest dislocations, and Peierls barriers can be readily overcome by assistance of thermal activation which in turn causes reduce the applied stress needed for dislocation passing obstacles [19]. Considering the uniform dispersity of CNTs at the grain boundaries, accumulating the mobile dislocations behind tough obstacles such as grain boundaries and CNT at border regions of the UFG grains, as well as forest dislocations inside the UFG grains. The accumulation of dislocations back of the CNTs could generate a stacked dislocation lines back of the grain boundaries as specified by blue rectangular in Figure 3, 4 . Accordingly, the probability of dislocation annihilation is decreased, and dislocation generation and accumulation gradually overtook its annihilation as the governing mechanism of deformation [15] as the imposed strain caused by conventional rolling process increases.

The mean grain size measurements for all the studied conditions are listed in Figure 5. the main results are that the grain size decreases as the thickness reduction increases for both the reinforcement percentages; in addition, the composite with $1.5 \%$ of carbon nanotubes reveals finer grain sizes with respect to the material with $1.0 \%$ of CNTs, evolving towards an equiaxed structure. 


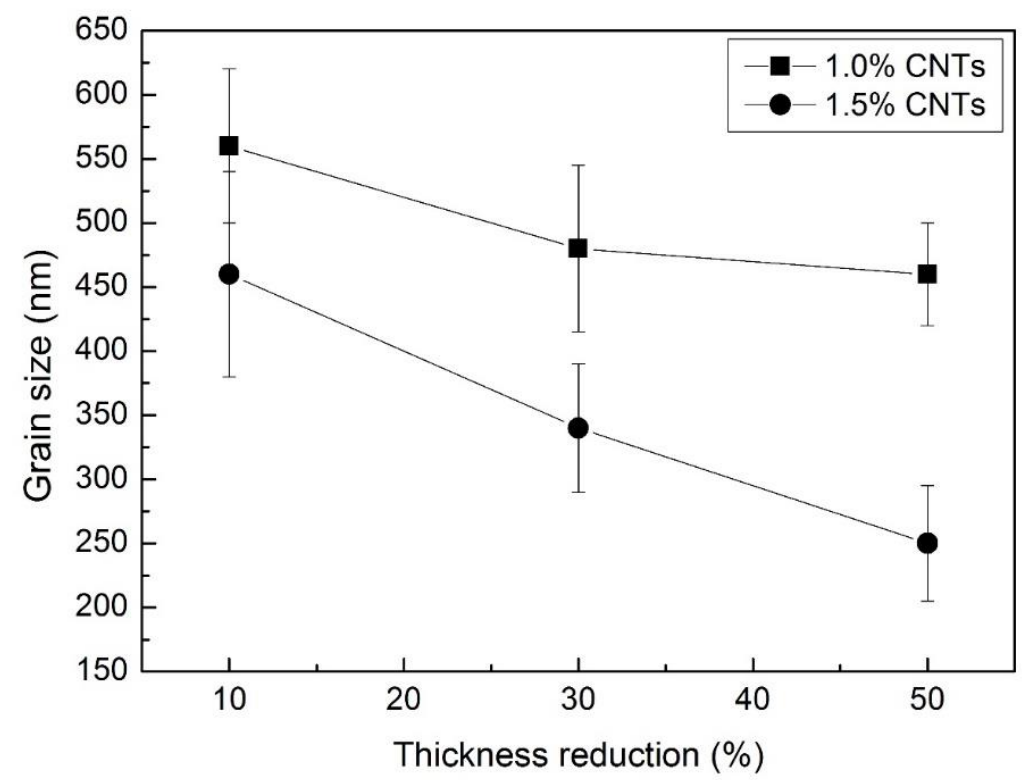

Figure 5: CNTs/Al composites grain size as a function of the thickness reduction and of the CNTs content.

The uniform distribution of CNTs is confirmed through the observation of EBSD maps shown in Figure 6 on the normal direction (ND) of CNT/Al rolled composites. There was an obvious equiaxed structure to some extent elongated grains along with RD in both 1 and $1.5 \mathrm{wt} . \%$ of CNTs/ Al. It can be seen that CNTs were found to be aligned unidirectionally to some extent, which should be the RD due to the shear stress during rolling process [65].
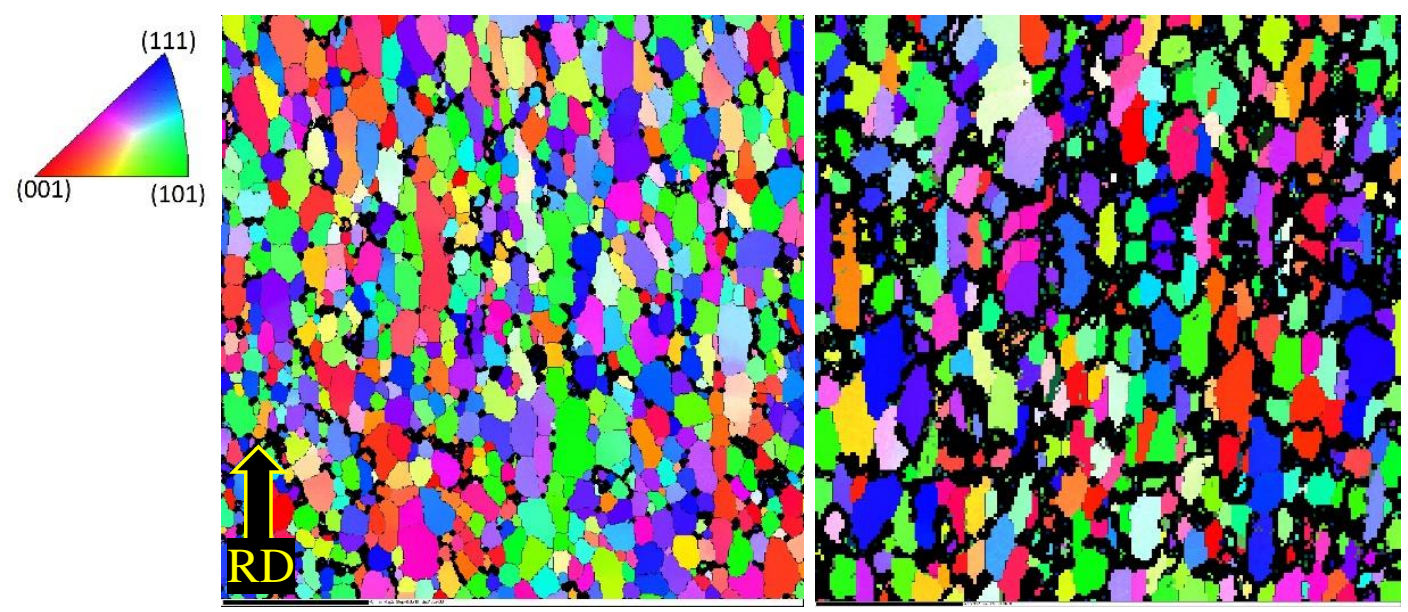
Figure 6: EBSD maps of the CNTs/Al composites with $1.0 \%$ (a) and $1.5 \%$ (b) of carbon nanotubes. Both maps belong to the material deformed with $50 \%$ of thickness reduction.

The grain size in equiaxed structure was determined primarily by the amount of the shear deformation the Al powders experienced during milling especially LSBM and then followed by thickness reduction of the conventional rolling. With increasing thickness reduction, the UFG grains structure was gradually pronounced. The UFG Al grain in the $1 \mathrm{wt} . \%$ and $1.5 \mathrm{wt} . \% \mathrm{CNT} / \mathrm{Al}$ composite were found to have relative shear textures with the dominant $(001)<110>$ of rotated cube texture, consistent with the results observed in CNT/Al composites produced by SPS and hot rolling process [63, 65].

\section{Mechanical properties}

The tensile properties of the studied materials are shown in Figure 7. It is obvious that the flow stress is increased with increasing the thickness reduction of 10,30 and $50 \%$ for both 1 wt.\% and 1.5 wt. $\%$ CNT-Al composite, indicating that the flow stress has a dependency of both strain and consistent. In fact, as $1 \mathrm{wt} . \%$ of CNT content increased to $1.5 \mathrm{wt} . \%$, the flow stress increase for all the thickness reductions, indicating strength depends on the CNT content. Plus, the observed variations of total elongation are basically retributed to the strain hardening capacity especially at higher strain where the accumulated dislocation density is significant. Considering the concept of tensile ductility, it can be fairly pointed out that tensile ductility depends on the uniform accumulation of dislocations in the UFG grains. In fact, the strain hardening capability can be manifested by the ability of the accumulation of dislocation in grains which conversely related to grain size. So, it expected that by increasing the dislocation density, this criterion is improved as seen in Figure 7. 

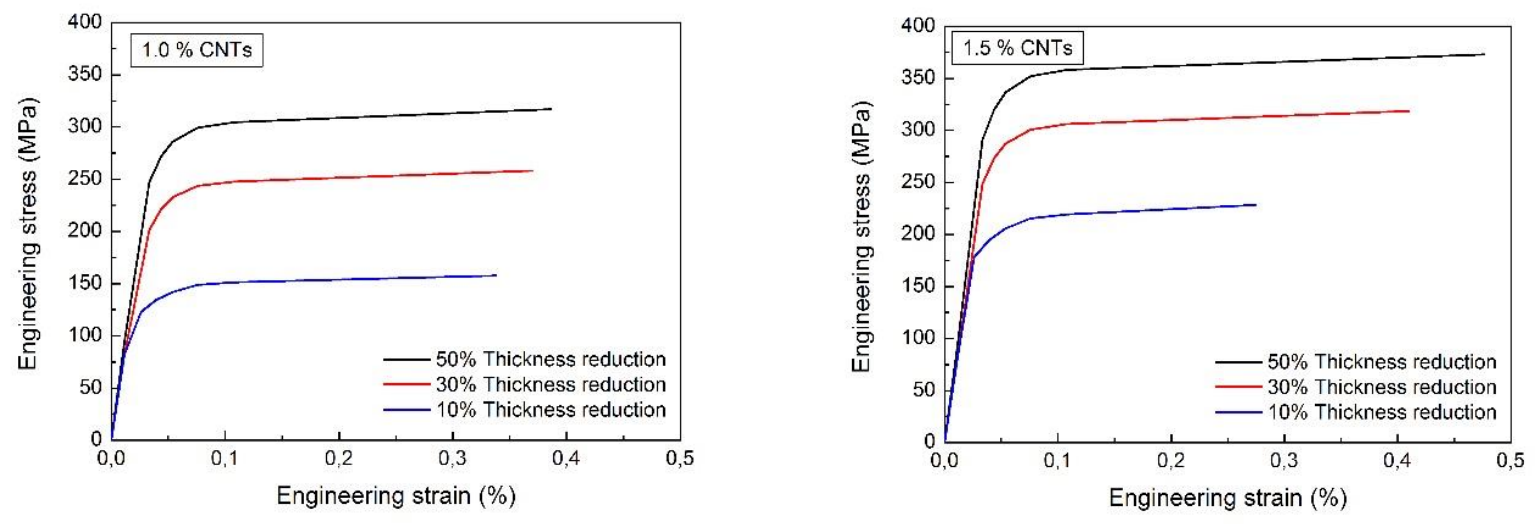

Figure 7: Tensile properties of the studied composites as a function of the CNTs percentage and of the thickness reduction per each composition.

The average dislocation velocity for a given strain rate and strain can be connected to strain rate by:

$v=\frac{\varepsilon^{\cdot}}{A b \varepsilon}$

Where $\mathrm{A}$ is an experimentally constant, equal to $10^{9}$, and $\varepsilon$ is the plastic strain, $\varepsilon^{\cdot}$ strain rate.

In fact, under higher strain, dislocation velocity decrease which resulted in enhancing dislocation number and more interactions between dislocations, leading to increase dislocation density. Therefore, it can be concluded that the internal stresses are increase, affecting the dislocation behavior especially in their generation, annihilation, and accumulation under different strains. It expected that by developing the accumulation of dislocation in CNT-enriched regions, the strain hardening capability increase, leading to enhance the tensile ductility of the CNT/Al composites.

The hardness behaviour is shown in Figure 8 . 


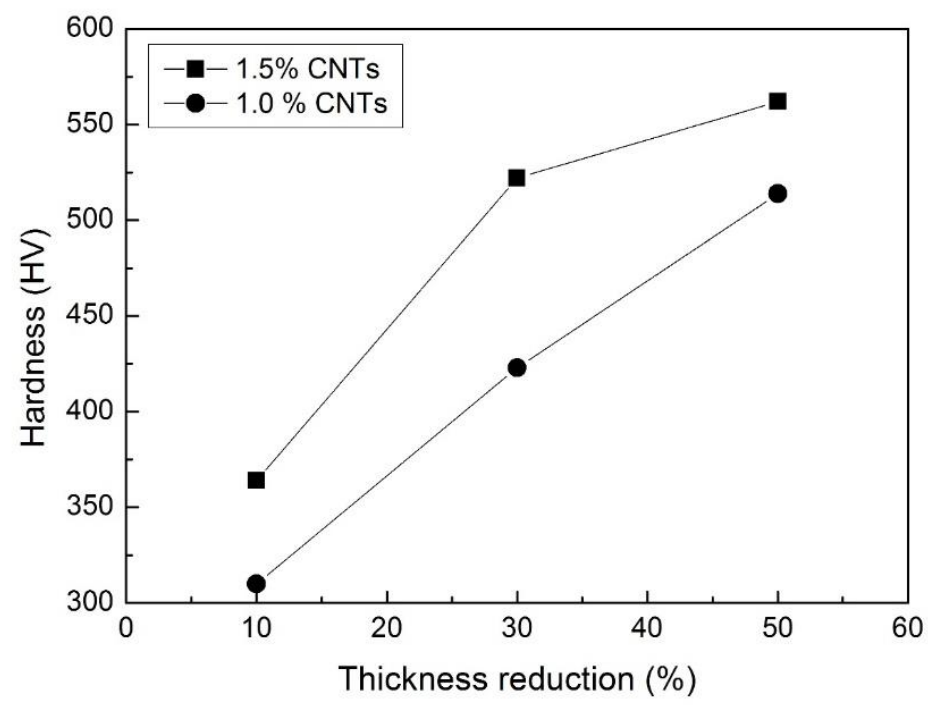

Figure 8: Hardness variation as a function of the CNTs percentage and of the thickness reduction.

The fracture surfaces of the tensile tested materials are shown in Figure 9.
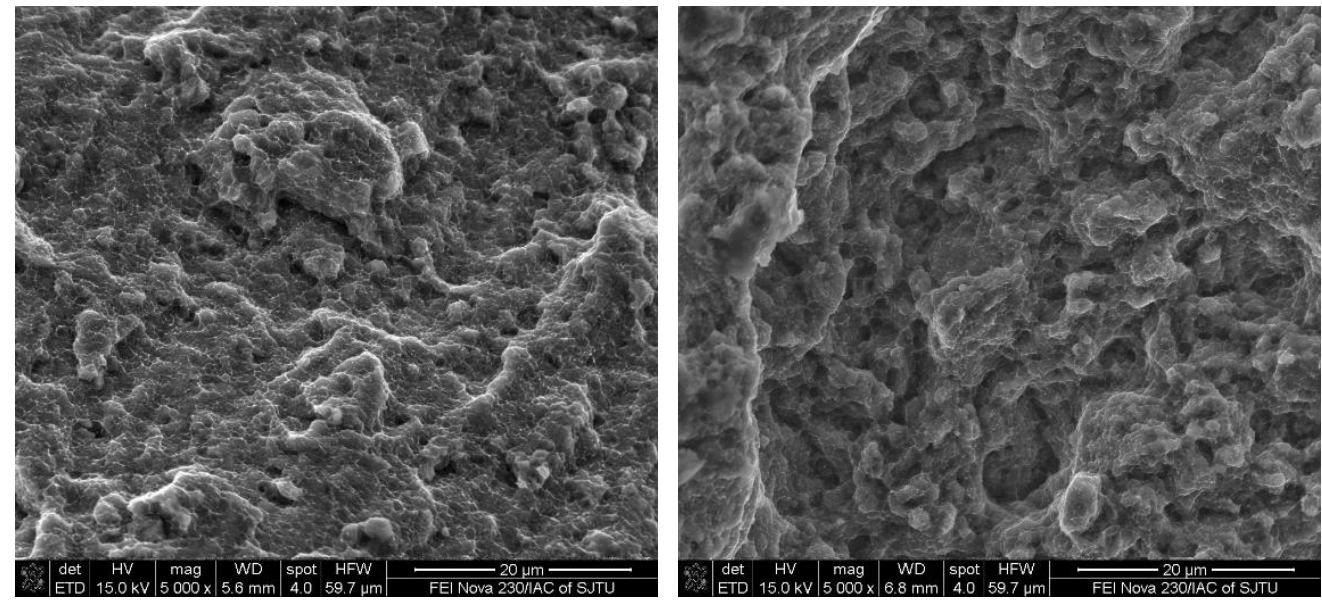

Figure 9: Fracture surfaces of the CNTs/Al composites with $1.0 \%$ (a) and $1.5 \%$ (b) of carbon nanotubes. Both maps belong to the material deformed with $50 \%$ of thickness reduction. 
The fracture surfaces aspect reveals a uniform distribution of very fine dimples replying the materials grain size. The main difference is represented by the more pronounced voids coalescence with formation of larger craters in the $1.5 \%$ CNTs reinforced material with respect to the $1.0 \% \mathrm{CNTs}$ one. It is believed that a larger concentration of carbon nanotubes leads to stress concentration in certain locations leading to intergranular fracture more pronounced as the nanotubes concentration increases.

\section{Conclusions}

The microstructural and mechanical evolution of carbon nanotubes reinforcing aluminium composites produced via flake metallurgy and rolling are described in the present paper. All the produced composites do not show carbon nanotubes agglomeration for all the selected reinforcing percentages. As the CNTs percentage increases, pronounced grain refinement is obtained. All the studied materials showed ultrafine grained structures. Grain refinement is more efficient as the rolling thickness reduction increases. The increase in deformation is accompanied with more pronounced textures and mechanical strength increase. The fracture surfaces observations revealed a very ductile behaviour of the tensile deformed materials.

\section{Declarations:}

The manuscript was not submitted to other journals for simultaneous consideration.

The submitted work is original and was not published elsewhere in any form or language.

Results were presented clearly, honestly, and without fabrication, falsification or inappropriate data manipulation.

No data, text, or theories by others are presented.

The authors have the consent to participate. 
The authors consent to publish the presented data.

Pasquale Cavaliere: Supervision, Data curation, Model development, Writing - original draft. Behzad Sadeghi: Investigation, Data curation, Model development. All authors read and contributed to the manuscript.

No funding was received for conducting this study.

The authors have no financial or proprietary interests in any material discussed in this article.

The authors have no competing interests.

The data are available on request to the corresponding author.

\section{References}

[1] Ovid'ko IA, Valiev RZ, Zhu YT (2018) Review on superior strength and enhanced ductility of metallic nanomaterials. Prog Mater Sci 94:462-540. https://doi.org/10.1016/j.pmatsci.2018.02.002 [2] Xu R, Tan ZQ, Fan GL, Ji G, Xiong DB, Guo Q, Su Y, Li Z, Zhang D (2018) High-strength $\mathrm{CNT} / \mathrm{Al}-\mathrm{Zn}-\mathrm{Mg}-\mathrm{Cu}$ composites with improved ductility achieved by flake powder metallurgy via elemental alloying. Composites A 111:1-11. https://doi.org/10.1016/j.compositesa.2018.05.012 [3] Jiang L, Li ZQ, Fan GL, Cao LL, Zhang D (2012) The use of flake powder metallurgy to produce carbon nanotube (CNT)/aluminum composites with a homogenous CNT distribution. Carbon 50(5):1993-1998. https://doi.org/10.1016/j.carbon.2011.12.057

[4] Cavaliere P, Sadeghi B, Shabani A (2017) Carbon nanotube reinforced aluminum matrix composites produced by spark plasma sintering. J Mater Sci 52(14):8618-8629. https://doi.org/10.1007/s10853-017-1086-6

[5] Bakshi SR, Agarwal A (2011) An analysis of the factors affecting strengthening in carbon $\begin{array}{llll}\text { nanotube } & \text { reinforced } & \text { aluminum } & \text { Carbon } 2 \text { :533-544. }\end{array}$ https://doi.org/10.1016/j.carbon.2010.09.054 
[6] Sadeghi B, Shamanian M, Cavaliere P, Ashrafizadeh F (2018) Effect of processing parameters on the microstructural and mechanical properties of aluminum-carbon nanotube composites produced by spark plasma sintering. Int J Mater Res 109(10):900-909. https://doi.org/10.3139/146.111686

[7] Sadeghi B, Cavaliere P, Perrone A (2020) Effect of Al2O3, SiO2 and carbon nanotubes on the microstructural and mechanical behavior of spark plasma sintered aluminum based nanocomposites. Particul Sci Technol 38(1):7-14. https://doi.org/10.1080/02726351.2018.1457109

[8] Fan GL, Jiang Y, Tan ZQ, Guo Q, Xiong DB, Su YS, Lin R, Hu L, Li Z, Zhang D (201). Enhanced interfacial bonding and mechanical properties in CNT/Al composites fabricated by flake powder metallurgy. Carbon 130:333-339. https://doi.org/10.1016/j.carbon.2018.01.037

[9] Jiang Y, Wang D, Liang S, Cao F, Zou J, Xiao P (2019) Effect of local alloying on interfacial bonding in laminated copper matrix composites reinforced by carbon nanotubes. Mater Sci Eng A 748:173-179. https://doi.org/10.1016/j.msea.2019.01.013

[10] Baig Z, Mamat O, Mustapha M (2018) Recent Progress on the Dispersion and the Strengthening Effect of Carbon Nanotubes and Graphene-Reinforced Metal Nanocomposites: A Review. Crit Rew Solid State 43(1):1-46. https://doi.org/10.1080/10408436.2016.1243089

[11] Wu C, Ma WX, Chen YP, Li Y, Chen Y, Li J (2014) Progress of the Current Interface Research on Carbon Nanotubes Reinforced Aluminum-matrix Composites. Int J Manuf Mater Mech Eng 842:196-200. https://doi.org/10.4028/www.scientific.net/AMR.842.196

[12] Tjong SC (2013) Recent progress in the development and properties of novel metal matrix nanocomposites reinforced with carbon nanotubes and graphene nanosheets. Mater Sci Eng $\mathrm{R}$ 74(10):281-350. https://doi.org/10.1016/j.mser.2013.08.001

[13] Bakshi SR, Lahiri D, Agarwal A (2010) Carbon nanotube reinforced metal matrix composites-a review. Int Mater Rev 55(1):41-64. https://doi.org/10.1179/095066009X12572530170543

[14] Kwon H, Cho S, Leparoux M, Kawasaki A. Dual-nanoparticulate-reinforced aluminum matrix composite materials. Nanotechnology 2012;23(22):225704. https://doi.org/10.1088/0957$4484 / 23 / 22 / 225704$ 
[15] Chen M, Fan G, Tan Z, Xiong D, Guo Q, Su Y, Zhang J, Li Z, Naito M, Zhang D (2018) Design of an efficient flake powder metallurgy route to fabricate CNT/6061Al composites. Mater Des 142:288-296. https://doi.org/10.1016/j.matdes.2018.01.044

[16] Yang X, Liu E, Shi C, He C, Li J, Zhao N, Kondoh K (2013) Fabrication of carbon nanotube reinforced Al composites with well-balanced strength and ductility. J Alloys Compd 563:216-220. https://doi.org/10.1016/j.jallcom.2013.02.066

[17] Fan GL, Xu R, Tan ZQ, Zhang D, Li ZQ (2014) Development of Flake Powder Metallurgy in Fabricating Metal Matrix Composites: A Review. Acta Metall Sin-Engl 27(5):806-815. https://doi.org/10.1007/s40195-014-0148-x

[18] Xu R, Tan Z, Xiong D, Fan G, Guo Q, Zhang J, Su Y, Li Z, Zhang D (2017) Balanced strength and ductility in CNT/Al composites achieved by flake powder metallurgy via shift-speed ball milling. Composites A 96:57-66. https://doi.org/10.1016/j.compositesa.2017.02.017

[19] Wei H, Li ZQ, Xiong DB, Tan ZQ, Fan GL, Qin Z, Zhang D (2014) Towards strong and stiff carbon nanotube-reinforced high-strength aluminum alloy composites through a microlaminated architecture design. Scripta Mater 75:30-33. https://doi.org/10.1016/j.scriptamat.2013.11.014

[20] Chen B, Shen J, Ye X, Imai H, Umeda J, Takahashi M, Kondoh K (2017) Solid-state interfacial reaction and load transfer efficiency in carbon nanotubes (CNTs)-reinforced aluminum matrix composites. Carbon 114:198-208. https://doi.org/10.1016/j.carbon.2016.12.013

[21] Zhou WW, Yamaguchi T, Kikuchi K, Nomura N, Kawasaki A (2017) Effectively enhanced load transfer by interfacial reactions in multi-walled carbon nanotube reinforced Al matrix composites. Acta Mater 125:369-376. https://doi.org/10.1016/j.actamat.2016.12.022

[22] Yu ZY, Tan ZQ, Fan GL, Xiong DB, Guo Q, Lin RB (2018) Effect of interfacial reaction on Young's modulus in CNT/Al nanocomposite: A quantitative analysis. Mater Charact 137:84-90. https://doi.org/10.1016/j.matchar.2018.01.024 
[23] Jiang L, Li ZQ, Fan GL, Zhang D (2011) A flake powder metallurgy approach to Al2O3/Al biomimetic nanolaminated composites with enhanced ductility. Scripta Mater 65(5):412-415. https://doi.org/10.1016/j.scriptamat.2011.05.022

[24] Jiang L, Li ZQ, Fan GL, Cao LL, Zhang D (2012) Strong and ductile carbon nanotube/aluminum bulk nanolaminated composites with two-dimensional alignment of carbon nanotubes. Scripta Mater 66(6):331-334. https://doi.org/10.1016/j.scriptamat.2011.11.023

[25] Zhang LX, Wang YH, Yang XH, Li K, Ni S, Du Y, Song M (2017) Texture, Microstructure and Mechanical Properties of 6111 Aluminum Alloy Subject to Rolling Deformation. Mater Res Ibero Am J 20(5):1360-1368. https://doi.org/10.1590/1980-5373-mr-2017-0549

[26] Gu CF, Hoffman M, Toth LS, Zhang YD (2015) Grain size dependent texture evolution in severely rolled pure copper. Mater Charact 101:180-188. https://doi.org/10.1016/j.matchar.2015.02.003

[27] Jazaeri H, Humphreys FJ (2004) The transition from discontinuous to continuous recrystallization in some aluminium alloys. Acta Mater 52(11):3239-3250. https://doi.org/10.1016/j.actamat.2004.03.031

[28] Jazaeri H, Humphreys FJ (2004) The transition from discontinuous to continuous recrystallization in some aluminium alloys: II - annealing behaviour. Acta Mater 52(11):3251-3262. https://doi.org/10.1016/j.actamat.2004.03.031

[29] Kwon H, Kawasaki A (2009) Extrusion of spark plasma sintered aluminum-carbon nanotube composites at various sintering temperatures. J Nanosci Nanotechnol 9(11):6542-6548. https://doi.org/10.1166/jnn.2009.1357

[30] Liu XQ, Li CJ, Eckert J, Prashanth KG, Renk O, Teng L, Liu Y, Bao R, Tao J, Shen T, Yi J (2017) Microstructure evolution and mechanical properties of carbon nanotubes reinforced Al matrix composites. Mater Charact 133:122-132. https://doi.org/10.1016/j.matchar.2017.09.036 
[31] Kwon H, Park DH, Silvain JF, Kawasaki A (2010) Investigation of carbon nanotube reinforced aluminum matrix composite materials. Comp Sci Technol 70(3):546-550. https://doi.org/10.1016/j.compscitech.2009.11.025

[32] Guo B, Ni S, Yi J, Shen R, Tang Z, Du Y, Song M (2017) Microstructures and mechanical properties of carbon nanotubes reinforced pure aluminum composites synthesized by spark plasma sintering and hot rolling. Mater Sci Eng A 698:282-288. https://doi.org/10.1016/j.msea.2017.05.068 [33] Fan G, Huang H, Tan Z, Xiong D, Guo Q, Naito M, Li Z, Zhang D (2017) Grain refinement and superplastic behavior of carbon nanotube reinforced aluminum alloy composite processed by cold rolling. Mater Sci Eng A 708:537-543. https://doi.org/10.1016/j.msea.2017.10.031

[34] Choi HJ, Bae DH (2011) Strengthening and toughening of aluminum by single-walled carbon nanotubes. Mater Sci Eng A 528(6):2412-2417. https://doi.org/10.1016/j.msea.2010.11.090

[35] Zare H, Jahedi M, Toroghinejad MR, Meratian M, Knezevic M (2016) Microstructure and mechanical properties of carbon nanotubes reinforced aluminum matrix composites synthesized via equal-channel angular pressing. Mater Sci Eng A 670:205-216. https://doi.org/10.1016/j.msea.2016.06.027

[36] Salimi S, Izadi H, Gerlich AP (2010) Fabrication of an aluminum-carbon nanotube metal matrix composite by accumulative roll-bonding. J Mater Sci 46(2):409-415. https://doi.org/10.1007/s10853$010-4855-\mathrm{Z}$

[37] Liu Z, Xiao B, Wang W, Ma Z (2012) Singly dispersed carbon nanotube/aluminum composites fabricated by powder metallurgy combined with friction stir processing. Carbon 50(5):1843-1852. https://doi.org/10.1016/j.carbon.2011.12.034

[38] Tokunaga T, Kaneko K, Horita Z (2008) Production of aluminum-matrix carbon nanotube composite using high pressure torsion. Mater Sci Eng A 490(1-2):300-304. https://doi.org/10.1016/j.msea.2008.02.022 
[39] Asgharzadeh H, Joo SH, Kim HS (2014) Consolidation of carbon nanotube reinforced aluminum matrix composites by high-pressure torsion. Met Trans A 45(9):4129-4137. https://doi.org/10.1007/s11661-014-2354-6

[40] Semenova IP, Raab GI, Valiev RZ (2019) Chapter 2 - Combined processing ECAP+TMP. In: Garbacz H, Semenova IP, Zherebtsov S, Motyka M, editors. Nanocrystalline Titanium: Elsevier; p. 21-35.

[41] Yoo SJ, Han SH, Kim WJ (2013) A combination of ball milling and high-ratio differential speed rolling for synthesizing carbon nanotube/copper composites. Carbon 61:487-500. https://doi.org/10.1016/j.carbon.2013.04.105

[42] Zare H, Jahedi M, Toroghinejad MR, Meratian M, Knezevic M (2016) Compressive, shear, and fracture behavior of $\mathrm{CNT}$ reinforced $\mathrm{Al}$ matrix composites manufactured by severe plastic deformation. Mater Des 106:112-119. https://doi.org/10.1016/j.matdes.2016.05.109

[43] Liu ZY, Xiao BL, Wang WG, Ma ZY (2013) Developing high-performance aluminum matrix composites with directionally aligned carbon nanotubes by combining friction stir processing and subsequent rolling. Carbon 62:35-42. https://doi.org/10.1016/j.carbon.2013.05.049

[44] Kim WJ, Lee TJ, Han SH (2014) Multi-layer graphene/copper composites: Preparation using high-ratio differential speed rolling, microstructure and mechanical properties. Carbon 69:55-65. https://doi.org/10.1016/j.carbon.2013.11.058

[45] Almotairy SM, Boostani AF, Hassani M, Wei D, Jiang ZY (2020) Effect of hot isostatic pressing on the mechanical properties of aluminium metal matrix nanocomposites produced by dual speed ball milling. J Mater Res Technol 9(2):1151-1161. https://doi.org/10.1016/j.jmrt.2019.11.043

[46] Alaneme KK, Okotete EA (2018) Recrystallization mechanisms and microstructure development in emerging metallic materials: A review. J Sci 4(1):19-33.

[47] Alaneme KK, Okotete EA (2019) Recrystallization mechanisms and microstructure development in emerging metallic materials: A review. Journal of Science: Advanced Materials and Devices. 4(1):19-33. https://doi.org/10.1016/j.jsamd.2018.12.007 
[48] Razavi-Tousi SS, Szpunar JA (2015) Effect of ball size on steady state of aluminum powder and efficiency of impacts during milling. Powder Technol 284:149-58. https://doi.org/10.1016/j.powtec.2015.06.035

[49] Rojac T, Kosec M, Malič B, Holc J (2006) The application of a milling map in the mechanochemical synthesis of ceramic oxides. J Eur Ceram Soc 26(16):3711-3716. https://doi.org/10.1016/j.jeurceramsoc.2005.11.013

[50] Liu ZY, Xiao BL, Wang WG, Ma ZY (2017) Modelling of carbon nanotube dispersion and strengthening mechanisms in Al matrix composites prepared by high energy ball milling-powder metallurgy method. Composites A 94:189-198. https://doi.org/10.1016/j.compositesa.2016.11.029 [51] Maurice D, Courtney T (1995) Modeling of mechanical alloying: Part II. Development of computational modeling programs. Met Trans A 26(9):2431-2435. https://doi.org/10.1007/BF02671257

[52] Maurice D. Courtney T (1994) Modeling of mechanical alloying: Part I. deformation, coalescence, bdand fragmentation mechanisms. Met Trans A 25(1):147-158. https://doi.org/10.1007/BF02646683

[53] Tan MJ, Zhang X (1998) Powder metal matrix composites: selection and processing. Mater Sci Eng A 244(1):80-85. https://doi.org/10.1016/S0921-5093(97)00829-0

[54] Xu R, Tan Z, Fan G, Ji G, Li Z, Guo Q, Li Z, Zhang D (2019) Microstructure-based modeling on structure-mechanical property relationships in carbon nanotube/aluminum composites. Int $\mathbf{J}$ Plasticity 120:278-295. https://doi.org/10.1016/j.ijplas.2019.05.006

[55] Liu H, Zhou J, Zhang S, Wang Y, Wang L, Dong S (2014) Modeling the strain-hardening effect and plastic deformation of nanocrystalline FCC metals dispersed with the finest grains. J Nanopart Res 16(6):2449. https://doi.org/10.1007/s11051-014-2449-4

[56] Zhu L, Lu J (2012) Modelling the plastic deformation of nanostructured metals with bimodal grain size distribution. Int J Plasticity 30-31:166-184. https://doi.org/10.1016/j.ijplas.2011.10.003 
[57] Razavi-Tousi S, Szpunar J (2015) Microstructural evolution and grain subdivision mechanisms during severe plastic deformation of aluminum particles by ball milling. Phil Mag 95(13):1425-1447. https://doi.org/10.1080/14786435.2015.1033028

[58] Kocks U, Mecking H (2003) Physics and phenomenology of strain hardening: the FCC case. Prog Mater Sci 48(3):171-273. https://doi.org/10.1016/S0079-6425(02)00003-8

[59] Malygin GA (2007) Analysis of the strain-rate sensitivity of flow stresses in nanocrystalline FCC and BCC metals. Phys Solid State 49(12):266-273. https://doi.org/10.1134/S1063783407120098

[60] Galindo-Nava EI, Sietsma J, Rivera-Díaz-del-Castillo PEJ (2012) Dislocation annihilation in plastic deformation: II. Kocks-Mecking Analysis. Acta Mater 60(6):2615-2624. https://doi.org/10.1016/j.actamat.2012.01.028

[61] Dong S, Zhou J, Hui D (2015) A quantitative understanding on the mechanical behaviors of carbon nanotube reinforced nano/ultrafine-grained composites. Int J Mechanical Sci 101-102:29-37. https://doi.org/10.1016/j.ijmecsci.2015.07.019

[62] Feaugas X, Haddou H (2007) Effects of grain size on dislocation organization and internal stresses developed under tensile loading in fcc metals. Phil Mag 87(7):989-1018. https://doi.org/10.1080/14786430601019441

[63] Sadeghi B, Cavaliere P, Roeen GA, Nosko M, Shamanian M, Trembošová V, Nagy S, Ebrahimzadeh N (2019) Hot rolling of MWCNTs reinforced Al matrix composites produced via spark plasma sintering. Adv Comp Hybrid Mater 2(3):549-570. https://doi.org/10.1007/s42114-019-000957

[64] Shi Y, Lu Y, Ni Z, Zhao L, Li Z, Xiong D-B, Zhou J, Guo Q (2020) Correlation Between Microstructural Architecture and Mechanical Behavior of Single-Walled Carbon NanotubeAluminum Composites. Met Trans A 51(2):545-551. https://doi.org/10.1007/s11661-019-05554-w [65] Yuan C, Tan Z, Fan G, Chen M, Zheng Q, Li Z (2019) Fabrication and mechanical properties of CNT/Al composites via shift-speed ball milling and hot-rolling. J Mater Res 34(15):2609-2619. 